\title{
Trends in cow numbers and culling rate in the Irish cattle population, 2003 to 2006
}

\author{
Maher, P. ${ }^{1}$, Good, M. ${ }^{1}$ and More, S.J. ${ }^{2}$
}

\author{
1 Department of Agriculture, Fisheries and Food, Kildare St., Dublin 2 \\ 2 Centre for Veterinary Epidemiology and Risk Analysis, UCD School of Agriculture, Food Science and Veterinary \\ Medicine, University College Dublin, Belfield, Dublin 4
}

\begin{abstract}
Cows are the main economic production units of Ireland's cattle industry. Therefore, demographic information, including overall numbers and survival rates, are relevant to the Irish agricultural industry. However, few data are available on the demographics of cows within a national population, either in Ireland or elsewhere, despite the recent development of comprehensive national cattle databases in many EU Member States. This study has sought: to determine the rate of cow culling from the national herd; to determine the rate of culling by type (dairy, beef), age, method of exit, date of exit and interval between last calving and exit; to calculate the national cow on-farm mortality rate; and to compare the Irish rates with published data from other countries. This work was conducted using data recorded in the national Cattle Movement Monitoring System (CMMS). Culling refers to the exit of cows from the national herd, as a result of death but regardless of reason, and cow-culling rate was calculated as the number of cow exits (as defined above) each year divided by the number of calf births in the same year. Culling rate was determined by type (dairy or beef), date of birth, method of exit (slaughter or on-farm death), month of exit and interval between last calving and exit. The average cow-culling rate during 2003 to 2006 was $19.6 \%$ (21.3\% for dairy, $18 \%$ for beef). While comparisons must be treated with caution, it concluded that the overall rates of culling in Ireland fell within published internationally accepted norms. The on-farm mortality rate of 3.2-4.1\% was similar to that reported in comparable studies.
\end{abstract}

Key Words: abattoir slaughter, CMMS, cull cow, national herd turnover rate, on-farm-death, population balance

Corresponding author:

Irish Veterinary Journal

Margaret Good, Department of Agriculture, Fisheries and Food,

Kildare St., Dublin 2

Email: margaret.good@agriculture.gov.ie

Phone: 016072265

Fax: 016072866

\section{Introduction}

Cows are the main economic production units of Ireland's cattle industry. Therefore, demographic information, including overall numbers and survival rates, are relevant to the Irish agricultural industry. However, few data are available on the demographics of cows within a national population, either in Ireland or elsewhere, despite the recent development of comprehensive national cattle databases in many EU Member States. Previous studies of culling in Ireland have focused on small numbers of animals in well-managed herds with good on-farm records. Studies by Crosse and O'Donovan (1998) and Crosse et al. (undated) were directed more at the 'reasons' for culling in well-managed dairy herds. A similar approach has generally been described in published studies from other countries.

The policy environment throughout the European Union may affect culling decisions. In 2003, reforms to the Common Agricultural Policy (CAP) led to the introduction of direct payments and the principle of decoupled support (Anon., 2003). Decoupled payments are typically based on the historical use of an input like land so benefits are capitalised into the value of the asset, benefiting the owner of the land, and in Ireland the vast majority of 'owners' are the actual farmers of the land. It is widely anticipated that decoupling will decrease cattle numbers over time. The national movement database (the Cattle Movement Monitoring System, CMMS), proves an opportunity to investigate the demographics of cows within the national herd. Summary information from this database have been prepared annually (CMMS 2003, 2004, 2005 and 2006), including figures for slaughter and on-farm deaths. However, to this point, these relate to the full population but not separately for cows. Using CMMS, this study has sought: to determine the rate of cow culling from the national herd; to determine the rate of culling by type (dairy, beef), age, method of exit, date of exit and interval between last calving and exit; to calculate the national cow on-farm mortality rate; and to compare the Irish rates with published data from other countries. In addition, this study provides the basis for preliminary assessment of the impact of CAP reforms on cow numbers in Ireland.

\section{Materials and methods \\ The national database}

In response to the BSE crisis during the 1990s, the European Commission legislated for the establishment of a National Movement Database by means of Council Regulation (EC) No 820/97 (Anon., 1997), which was in turn replaced by Regulation (EC) No 1760/2000 (Anon., 2000). The 
Department of Agriculture, Fisheries and Food (DAFF) over a three-year period introduced a comprehensive system of movement notifications, which included the recording on the database of all bovine births, imports, movements, slaughterings, exports and deaths. As required under the Regulation, the database was fully operational by January 1,2000 . Data is collected from a variety of sources including keepers, marts, abattoirs, export locations and knackeries and only data that has fulfilled relevant validation criteria is accepted onto the CMMS database.

Bovine population activity and trading patterns varied over the four years of this study and during this time the CMMS database recorded, approximately, the following transactions annually:

i. $\quad 1.7$ million movements to slaughter at 45 export approved abattoirs;

ii. 90,000 movements to slaughter at 400 Local Authority abattoirs;

iii. 220,000 on-farm deaths, the vast majority of which had their carcases collected and disposed of in approximately 30 category 2 intermediate plants (knackeries);

iv. 1.6 million movements through 100 marts (cattle markets);

v. 180,000 animals exported through three ports and 15 assembly centres;

vi. 800,000 direct farm-to-farm movements, between 125,000 registered holdings and keepers; and

vii. 2.2 million calf birth registrations, with data collected on date of birth, breed, sex, birth holding, breed of sire and dam and tag number of dam. The dam is only eligible if recorded as a cow that was present on the birthing holding on the relevant date of birth.

In addition, prior to de-coupling, the database also recorded all premiums paid to farmers and in respect of individual animals.

\section{Data extraction}

This work was conducted using the annual CMMS extracts, compiled by DAFF's Information Systems Division shortly after each year-end, that were used as the basis of the CMMS Annual Statistics Report for 2003, 2004, 2005 and 2006. Each extract included records of all movements to slaughter at export-approved abattoirs (i. in the aforementioned list), all movements to slaughter at Local Authority abattoirs (ii) and knackery collection and disposal of on-farm deaths (iii.). Subsequently, the authors retained only those records that related to cows. In this study, a cow was defined as a female animal to which at least one calf had been registered; therefore, eligible records were identified after determining the 'last calving date', if present. In each yearly extract, heifers (a subset of cows) were identified based on the date of first recorded calving.

\section{Data analysis}

In this study, culling refers to the exit of cows from the national herd, as a result of death but regardless of reason. Therefore, culling encompasses slaughter (whatever the
Table 1: Animal type (dairy, beef), by breed (code, percentage based on Irish cow population in 2005 ) as recorded in the Irish Cattle Movement Monitoring System (CMMS) database

\begin{tabular}{l|l|}
\hline $\begin{array}{l}\text { A dairy breed (48.2\%) is } \\
\text { any animal recorded on } \\
\text { the database as one of the } \\
\text { following breeds: }\end{array}$ & $\begin{array}{l}\text { Beef breeds (50.4\%) are } \\
\text { any other breeds, the chief } \\
\text { amongst them being: }\end{array}$ \\
\hline $\begin{array}{l}\text { FR (Friesian/Holstein) }-47.1 \% \\
\text { AY (Ayrshire) }\end{array}$ & AA (Angus) $-6.3 \%$ \\
\hline BS (Brown Swiss) & BB (Belgian Blue) - 2.6\% \\
\hline RD (Danish Red) & CH (Charolais) $-12.1 \%$ \\
\hline GU (Guernsey) & HE (Herford) $-7.7 \%$ \\
\hline JE (Jersey) & LM (Limousin) $-12.1 \%$ \\
\hline KE (Kerry) & SI (Simmental) $-7.8 \%$ \\
\hline MO (Montbelliarde) - 1.1 \% & SH (Shorthorn) $-1.8 \%{ }^{b}$ \\
\hline MY (MRI/MRY) Meuse Rhine \\
(Y) Issel & SD South Devon \\
\hline NO (Normande) & \\
\hline NR (Norwegian) & \\
\hline SR (Swedish Red) & \\
\hline SA (Salers) & \\
\hline SD (South Devon) & \\
\hline
\end{tabular}

a. Breed percentages are presented for $98.6 \%$ of the 2005 cow population. The shortfall $(1.4 \%)$ includes all other breeds (that is, those without a supplied percentage) b. Although some Shorthorn cows may be milked in dairies, in this study all were regarded as beef animals

reason, including disease control) and on-farm death, but not disposal of surplus stock from an individual herd, by export or otherwise, where the removed animal continued to give further production and/or economic return for a new keeper. The cow culling rate was calculated as the number of cow exits (as defined above) each year divided by the number of calf births in the same year. The cow mortality rate was calculated as the number of on-farm deaths each year divided by the number of births in the same year. In each case, the number of births was used as a proxy for the number of 'productive' cows. Furthermore, each numerator was calculated from the extracted CMMS datafiles, and each denominator from the relevant published CMMS Annual Statistics report. Data from these reports was used to determine the number of cattle in the national herd.

Data management and extraction was conducted using FoxPro® Database (Microsoft Corporation, Redmond, WA, USA), and data analysis using Microsoft Excel ${ }^{\circledR}$ (Microsoft Corporation, Redmond, WA, USA). Culling rate was determined by type (dairy or beef; Table 1 ), date of birth (not recorded prior to 1996), method of exit (slaughter or on-farm death), month of exit, and interval between last calving and exit.

Table 2: The total number of animals in the Irish cattle population at the end of years 2003 to 2006, as reported previously (CMMS, 2003, 2004, 2005, 2006)

\begin{tabular}{l|l|l|l|l|l} 
End of year: & 2003 & 2004 & 2005 & 2006 & Average \\
\hline
\end{tabular}

\begin{tabular}{l|l|l|l|l|l} 
Total number & $6,589,974$ & $6,501,788$ & $6,532,706$ & $6,321,823$ & $6,486,573$
\end{tabular} of cattle

\section{Results}

\section{The national herd}

The number of cattle in the national herd at year's end remained relatively constant during 2003 to 2006 (Table 
2). Cattle numbers in 2006 were noticeably lower than in earlier years (Figure 1). During this period, there was substantial, but relatively consistent, within-year fluctuation, from a low of approximately 6.5 million at the end of each year to a high of approximately 7.1 million at the end of May following the spring calving season (Figure 1). The number of calf birth registrations was relatively constant during 2003 to 2006, both for dairy and beef breeds (Table 3).

\section{Cows culled}

The recorded number of calves entering (by year, type and age of cull-cow replacement) and cows exiting (by year, type and method of exit) the national Irish cattle herd, during 2003 to 2006 is presented in Table 3. The overall culling rate, by year and type, is presented in Figure 2 . There was an increase in the recorded number of calf birth registrations in 2004 compared with 2003, both for dairy and beef (Table 3). During 2005 and 2006, there was also an increase in the recorded number of cows culled, both for dairy and beef, but a drop in the number of calves registered, particularly in dairy (Table 3 ). The cow culling rate was higher in dairy than beef, and the ratio of the culling rates for dairy to beef increasing progressively over time (Table 3).

The age at which cows were culled, by year, by type and by method of exit, during 2003 to 2006 is presented in Table 4. Table 5 provides details of the interval from the last recorded calving date to culling by year, by type and by means of exit, thus giving information as to when during

Table 3: Recorded number of calves entering (by year, type and dam age) and cows exiting (by year, type and method of exit) the national Irish cattle herd, during 2003 to 2006

\begin{tabular}{|c|c|c|c|c|}
\hline & 2003 & 2004 & 2005 & 2006 \\
\hline \multicolumn{5}{|l|}{ 1. Recorded calf entries } \\
\hline \multicolumn{5}{|l|}{ 1a. All dams } \\
\hline Dairy & $1,064,861$ & $1,066,342$ & $1,049,014$ & $1,038,520$ \\
\hline Beef & $1,079,819$ & $1,104,834$ & $1,101,051$ & $1,092,742$ \\
\hline Total & $2,144,680$ & $2,171,176$ & $2,150,065$ & $2,131,262$ \\
\hline \multicolumn{5}{|l|}{ 1b. Heifer dams only } \\
\hline Dairy & 220,114 & 223,974 & 235,477 & 235,395 \\
\hline (Average dam calving age [months]) & [29.3] & [28.8] & {$[28.6]$} & {$[28.8]$} \\
\hline Beef & 187,167 & 190,517 & 187,504 & 190,528 \\
\hline (Average dam calving age [months]) & [31.3] & [31.2] & [31] & [31] \\
\hline Total & 407,281 & 414,491 & 422,981 & 425,923 \\
\hline (Average dam calving age [months]) & [30.2] & [29.9] & {$[29.7]$} & [29.8] \\
\hline \multicolumn{5}{|l|}{ 2. Recorded cow exits } \\
\hline \multicolumn{5}{|l|}{ 2a. Slaughter } \\
\hline Dairy & 170,216 & 189,150 & 189,020 & 192,653 \\
\hline (\%) & $(16.0 \%)$ & $(17.7 \%)$ & $(18.0 \%)$ & $(18.6 \%)$ \\
\hline Beef & 158,946 & 154,922 & 157,281 & 170,522 \\
\hline (\%) & $(14.7 \%)$ & $(14.0 \%)$ & $(14.3 \%)$ & $(15.6 \%)$ \\
\hline Total & 329,162 & 344,072 & 346,301 & 363,175 \\
\hline 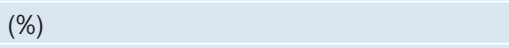 & $(15.3 \%)$ & $(15.8 \%)$ & $(16.1 \%)$ & $(17.0 \%)$ \\
\hline \multicolumn{5}{|l|}{ 2b. On-farm deaths } \\
\hline Dairy & 34,949 & 36,676 & 40,092 & 45,548 \\
\hline (\%) & $(3.3 \%)$ & $(3.4 \%)$ & $(3.8 \%)$ & $(4.4 \%)$ \\
\hline Beef & 34,342 & 33,684 & 36,234 & 40,973 \\
\hline (\%) & $(3.2 \%)$ & $(3.0 \%)$ & $(3.3 \%)$ & $(3.7 \%)$ \\
\hline Total & 69,291 & 70,360 & 76,326 & 86,521 \\
\hline (On-farm mortality rate, \%) & $(3.2 \%)$ & $(3.2 \%)$ & $(3.5 \%)$ & $(4.1 \%)$ \\
\hline \multicolumn{5}{|l|}{ 2c. Slaughter and on-farm deaths } \\
\hline Dairy & 205,165 & 225,826 & 229,112 & 238,201 \\
\hline (Cow culling rate, $\%)$ & $(19.3 \%)$ & $(21.2 \%)$ & $(21.8 \%)$ & $(22.9 \%)$ \\
\hline $\begin{array}{l}\text { [Difference between cow exits and heifer } \\
\text { entries] }\end{array}$ & 14,949 & $-1,852$ & 6,365 & $-2,806$ \\
\hline Beef & 193,288 & 188,606 & 193,515 & 211,495 \\
\hline (Cow culling rate, \%) & $(17.9 \%)$ & $(17.1 \%)$ & $(17.6 \%)$ & $(19.4 \%)$ \\
\hline $\begin{array}{l}\text { [Difference between total cow exits and } \\
\text { heifer entries] }\end{array}$ & $-6,121$ & 1,911 & $-6,011$ & $-20,967$ \\
\hline Total & 398,453 & 414,432 & 422,627 & 449,696 \\
\hline (Cow culling rate, \%) & $(18.6 \%)$ & $(19.1 \%)$ & $(19.7 \%)$ & $(21.1 \%)$ \\
\hline $\begin{array}{l}\text { [Difference between total cow exits and } \\
\text { heifer entries] }\end{array}$ & 8,828 & 59 & 354 & $-23,773$ \\
\hline
\end{tabular}




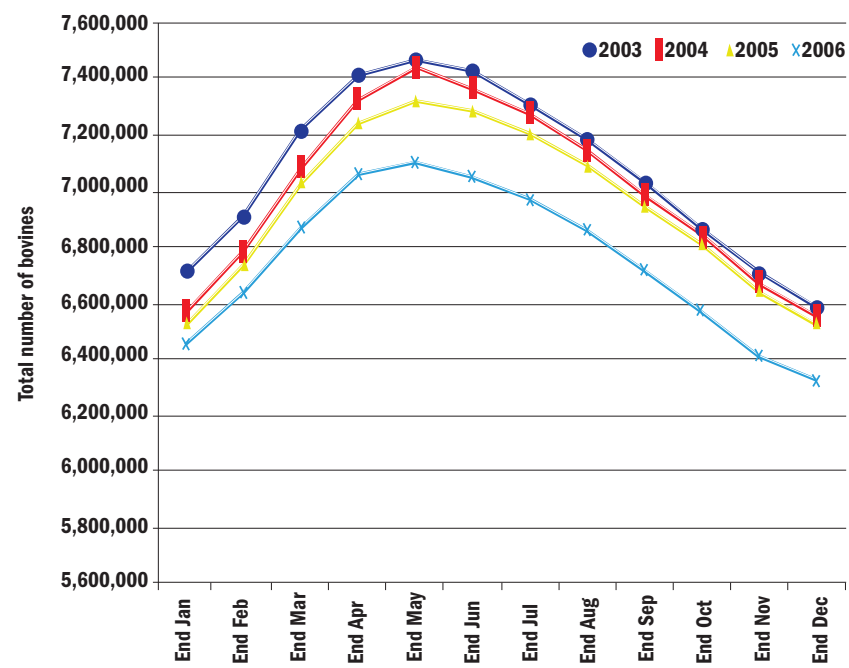

Figure 1: Annual fluctuations in the total number of cattle in the Irish national cattle herd, by year, between 2003 and 2006 .

the subsequent lactation and during the productive cycle of the cow she was culled. Table 6 shows the numbers of cows culled by year, by calendar month and by means of exit.

\section{Discussion}

\section{Calculating culling rates}

In this study, culling refers to the removal of cows from the national herd as a result of slaughter rate and onfarm death. With the exception of a small number of high genetic merit animals, few cows are exported live from Ireland. Our definition is in contrast to the use of 'culling' in many farm-based studies, where culling would encompass the disposal of surplus stock from an individual herd on the open market, by export or otherwise, where the removed animal will continue to give further production and/or economic return for a new keeper. Furthermore, some studies refer to involuntary culling as the removal of for instance 'infertile cows' and voluntary culling as the removal of low yielding cows (Crosse and O'Donovan, 1998). Our use of cull is equivalent to the 'herd turnover rate' as proposed by Hadley et al. (2006), and covers the removal of the cow from the national herd either 'voluntarily' or 'involuntarily' through her disposal in a slaughter plant or 'involuntarily' as an on-farm death. These, together with exports, constitute an 'exit' from the Irish database of live animals. Herd turnover rate is recommended as the term to represent the magnitude of removals from the herd (Fetrow et al., 2006).

In this study, the cow-culling rate was calculated using calf births as an estimate for cow numbers in any particular year. The authors acknowledge that there is the potential for both underestimation (cow infertility, pregnancy loss) and overestimation (multiple births) of the true number of cows, using this approach. This approach was taken, based on CMMS data available. While this has provided a valuable insight into culling in the Irish national cattle herd, comparison with other studies (which are generally based on intensive studies in a relatively small number of herds) needs to be conducted with care.

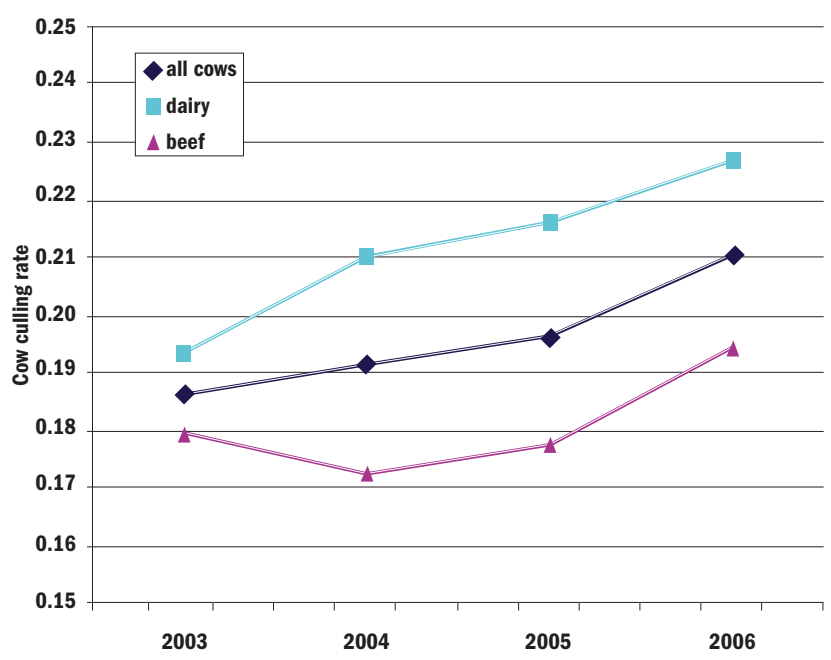

Figure 2: Changes in the cow-culling rate in the national Irish cattle herd, by year and type, during 2003 to 2006.

\section{The Irish cow population}

The whole bovine population fluctuates from a low of $6,464,038$ million animals at the start of January to a high of 7,103,634 million animals at the start of June (CMMS statistics report, 2006) and in same manner the number of 'cows' in the population also varies from day to day over the entire year as some 400,000 cows are slaughtered or die on-farm and are replaced by pregnant heifers calving. It is therefore difficult to determine with precision the total productive cow population for a given year. To illustrate, a cow and her replacement may both be present in the cow population simultaneously if a heifer has already calved and the cow being culled has not yet been slaughtered. Similarly, both are present during the same calendar year if a cow were culled in the early part of the year and her replacement (heifer) calves later in the same year.

The consistency in recorded births per year (Table 3 ) and the balance in the numbers of heifers entering and cows being culled reflect stability in the cow population year on year. In 2003, 407,281 heifers were recorded as calving for the first time and so entering the cow population, this is only slightly above $(8,828)$ the total number of cows culled in the same year $(398,453)$. In other words, the number of entries was roughly equivalent to the number of exits. However, in 2006 despite a rise in the number of heifers calving compared to 2003, there was a net loss of 23,773 cows from the national herd (equivalent to a fall of $1.1 \%$ ).

These data do give some indication of a fall in total cow numbers, and therefore in the total cattle population in 2006 (Figure 1). This was widely predicted as a result of the recent decoupling of EU support payments in Ireland. There was constant increase year on year of $0.4-0.6 \%$ in the overall cull rate, increasing from $18.6 \%$ in 2003 to $21.1 \%$ in 2006 (Table 3); within this increase however, the proportion of dairy cows slaughtered in 2004 was higher and the proportion of beef cows slaughtered in 2004 was lower. So for 2004 the cull rate increased but this was due to an increase in dairy cow culling. Table 3 also demonstrates that there is a difference in the proportion of dairy and beef cows slaughtered each year, e.g., in 2003, $16.0 \%$ of dairy 
Table 4: The number (percentage) of cows culled, by year, by age, by type and by means of exit (either slaughter or on-farm death, OFD)

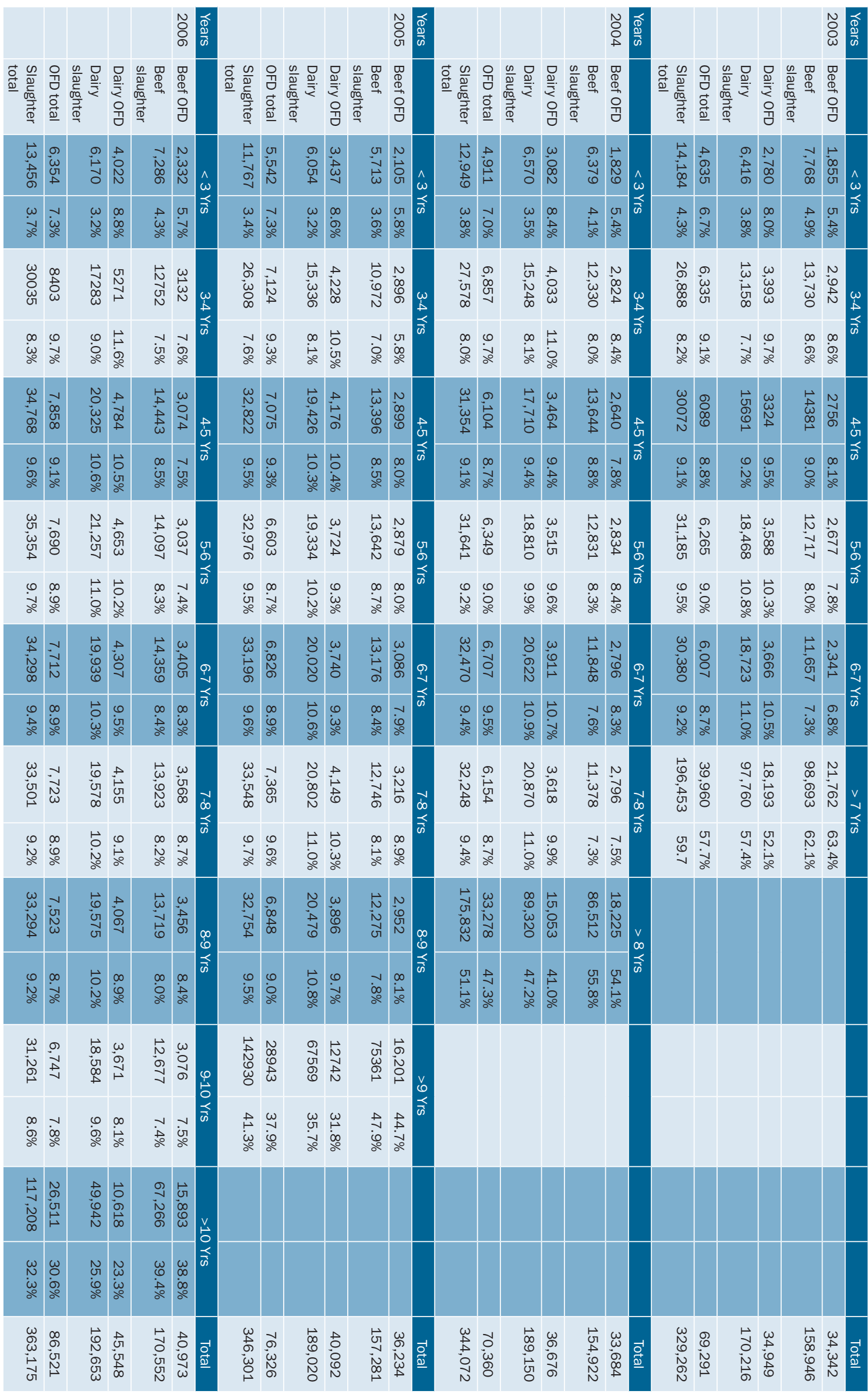


Table 5: The number of cows culled, by year, by interval since most-recent calving, by type and by means of exit (either slaughter or on-farm death, OFD)

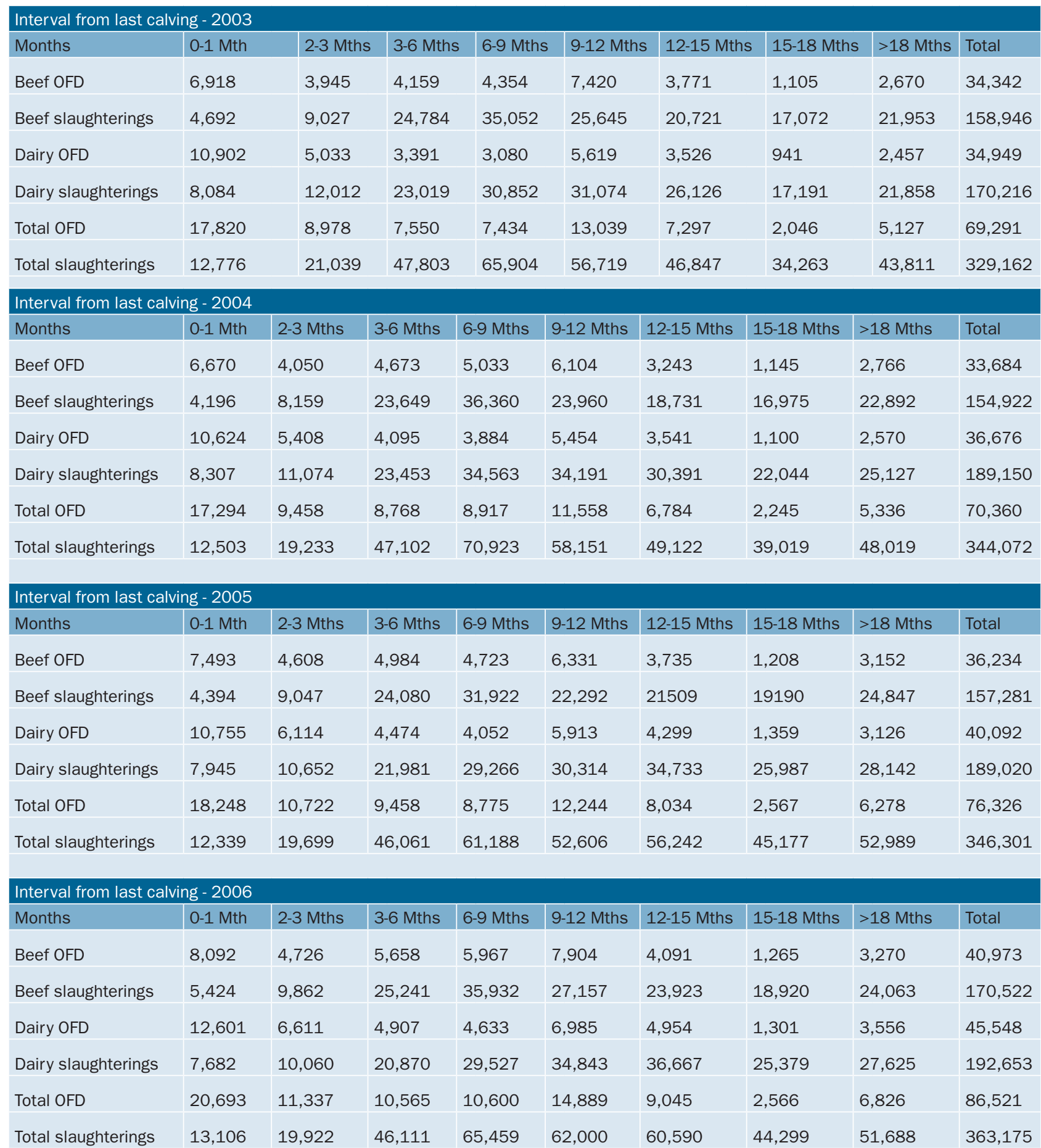

cows were slaughtered compared to $14.7 \%$ of beef cows slaughtered. Thus the absolute numbers of dairy cows has fallen (Table 3) while the number of beef cows has risen (Table 3), however the increase in beef cow slaughtering in 2006 (Table 3) may be the beginning of this trend in beef cows also. Table 3 gives the cow numbers and cull rate for dairy and beef cows. Any trends appearing will require ongoing monitoring over the next number of years as other market forces will influence farmer decisions in this regard. The most surprising figure to emerge from these data is the consistency of the annual percentage loss rate from the cohort population once the animals are older than four years (Table 4). The birth date of animals born prior to 1996 is not recorded on the database; it is not possible to further calculate the age breakdown of this $32.3 \%$ (2006) of the abattoir culls over 10 years old. Of the cull cows, some 8.6-9.7\% per year belong to each known age cohort population. Assuming the same proportion of losses in each age cohort as in the four-to 10 -year-old cohorts then it is probable that only about $5 \%$ of the cow population is over 13 years old.

The total number of beef cows in the cow population in 2005 is higher than the numbers of dairy cows (Table 1). The total numbers of on-farm deaths and animals 
Table 6: Number of cows culled by year, by month of exit and by means of exit (either slaughter or on-farm death, OFD)

\begin{tabular}{|l|l|l|l|l|l|l|l|l|l|l|}
\hline & 2003 & & 2004 & & 2006 & \multicolumn{2}{l|}{ Average } \\
\hline & Slaughter & OFD & Slaughter & OFD & Slaughter & OFD & Slaughter & OFD & Slaughter & OFD) \\
\hline Jan & 27,455 & 5,647 & 22,953 & 4,705 & 14,437 & 5,344 & 25,737 & 6,340 & 22,646 & 5,509 \\
\hline Feb & 23,207 & 7,812 & 21,509 & 6,819 & 21,361 & 7,150 & 25,324 & 8,387 & 22,850 & 7,542 \\
\hline Mar & 18,326 & 12,590 & 23,358 & 11,149 & 21,682 & 11,200 & 27,321 & 14,325 & 22,672 & 12,316 \\
\hline Apr & 19,773 & 11,402 & 20,671 & 10,759 & 22,609 & 11,491 & 23,310 & 13,747 & 21,591 & 11,850 \\
\hline May & 25,475 & 7,942 & 20,736 & 7,352 & 29,180 & 8,614 & 30,611 & 10,701 & 26,501 & 8,652 \\
\hline Jun & 27,173 & 4,380 & 28,081 & 4,326 & 32,208 & 5,487 & 35,589 & 5,201 & 30,763 & 4,849 \\
\hline July & 33,769 & 3,223 & 30,314 & 3,117 & 30,381 & 3,722 & 32,557 & 3,748 & 31,755 & 3,453 \\
\hline Aug & 25,358 & 2,811 & 31,446 & 3,424 & 33,536 & 3,731 & 31,481 & 3,457 & 30,455 & 3,356 \\
\hline Sep & 30,767 & 2,822 & 31,440 & 3,778 & 35,490 & 3,783 & 32,393 & 3,796 & 32,523 & 3,545 \\
\hline Oct & 34,429 & 3,033 & 36,454 & 4,889 & 34,166 & 4,766 & 33,593 & 6,001 & 34,661 & 4,672 \\
\hline Nov & 36,456 & 3,499 & 41,183 & 4,808 & 41,544 & 5,897 & 39,220 & 5,844 & 39,601 & 5,012 \\
\hline Dec & 26,974 & 4,130 & 35,927 & 5,234 & 29,707 & 5,141 & 26,039 & 4,974 & 29,662 & 4,870 \\
\hline Total & 329,162 & 69,291 & 344,072 & 70,360 & 346,301 & 76,326 & 363,175 & 86,521 & 345,678 & 75,625 \\
\hline
\end{tabular}

slaughtered (Table 4) for each age cohort to age 10 is also less for beef cows; confirming that there is a higher proportion $(\sim 54 \%)$ of beef cows over nine years of age in the cow population. In Ireland, beef cows survive longer than dairy cows.

\section{Number of on-farm deaths}

There are peaks in the number of on-farm deaths within one month and 9-12 months following the last recorded calving (Table 5). The former highlights the significance of a calving event in the life cycle of a cow. On average, $24.5 \%$ of all cows that die on-farm, die within one month of their last reported calving date. The latter accounts for $17.1 \%$ of on-farm deaths. We speculate that this may also be related to a calving or pre-calving event, but from which no live birth is recorded on the database. This accords with data from the study conducted by Sol et al. (1984) who also found a culling peak shortly after calving attributed to calving difficulties, mastitis, teat injuries and other health problems. In Ireland, because the majority of cows calve in the spring, on-farm deaths in cows peaks in March and April (Table 6).

\section{Number of cows slaughtered}

Cows are slaughtered at varying times post-calving with a peak between six and nine months after the last recorded calving date (Table 5). Since the majority of cows calve in the early part of the year, most cows are slaughtered in the autumn (Table 6). Sol et al. (1984), who also found a slaughter peak commencing some six months post calving, suggest that culling at the end of lactation is mainly a reflection of reproductive failure coupled with high prices. In general, farmers would prefer to cull a cow at the end of peak lactation and off pasture. Once an animal is housed, direct feeding costs become more expensive. Cows, however, are sent to the factory at various times during the year (Table 6). The data reflects that while an individual farmer may wish to remove a cow from the herd at the end of the grazing season, many such cows are then finished for slaughter by specialised cow finishers and thus slaughtered at any time and the distinction is not provided in this study. The higher numbers appear in the autumn as the grazing season finishes.

\section{Age and lactation number when culled}

Analysis of the data for the four years of this study shows that heifers in Ireland on average first calve aged between 29.7 and 30.2 months (dairy, 28.6-29.3 months; beef, 31.0-31.3 months) (Table 3). This average masks a wide spread in the actual recorded age of heifers when their first calf is registered, $<18$ months to $>38$ months, and gives no indication of the spring peak in Irish calving patterns. In Ireland, to coincide with the growth of grass, the majority of cows calve in springtime and, therefore, heifer calvings are planned to conform to this pattern. Forty-nine per cent of dairy heifers calved at 24 months plus/minus two months with $17 \%$ at 36 months plus/minus two months, reflecting this spring calving pattern particularly of the dairy sector. The 24-month peak for beef heifers is only $24 \%$, reflecting that their age calving pattern is more evenly distributed. The same pattern is repeated year-on-year for both beef and dairy breeds.

This data, in combination with Table 4, enabled us to determine in which lactation a cow was culled. Esslemont and Kossaibati (1997) found that cumulatively $41.3 \%$ of dairy cows sent for slaughter were removed by their third lactation. Sol et al. (1984) also reported an average age of culling of 5.7 years (third lactation) in their study population. In Ireland, the age of the dairy herd is likely to be somewhat older than this. During 2003-2005 and in $2006,32 \%$ and $35 \%$ cows were culled at less than six years of age, respectively (Table 4). Therefore, some 65-68\% of dairy cows were retained in the national herd into their fourth lactation and beyond.

\section{Comparing culling rates}

Crosse and O’Donovan (1998) found an average annual cull figure of $17.6 \%$ (range 15.2-22.6\%) for the period 1980 to 1985 in 22 well managed large Irish dairy herds. Furthermore, Crosse et al. (undated) found the average 
annual cull figure to be $15.2 \%$ for the period 1990 to 1994 . However, in each case, the sample size was small. These rates and studies related to culling only in dairy herds in Ireland, and while they represent all age cohorts, the rates include both voluntary and non-voluntary reasons for culling but do not include on-farm deaths. Reports published from the UK (Esslemont and Kossaibati, 1997) and Australia (Stevenson and Lean, 1998) describe average annual involuntary culling rates of $22 \%$ and $24 \%$ respectively, in dairy herds. Involuntary culling in these reports consists of all cow disposals, apart from disposals due to cows being surplus to requirements or old age. Furthermore, comparable studies from the UK. (Whitaker et al., 2000; Whitaker et al., 2004) report culling rates of $22.1 \%$, and 22.6\%, and from the Netherlands (Sol et al., 1984) culling rates in dairy herds of $18.8 \%$ in 1951, and between 23.1 and 33\% during 1968-1983. Hadley et al. (2006) analysed culling statistics over a seven-year period, 1993-1999, across 10 US states, and found an average culling rate (slaughter and death) of $31.6 \%$, which was marginally above the stated optimal figure of $19-29 \%$. These studies appear to have been conducted in closely managed herds, many with computerised records. In the current study, the reported annual average national herdculling rate was $19.6 \%$ (dairy average $21.3 \%$; beef average $18 \%$ ), which covers all types of management in all types of herds (Table 3).

\section{Comparing on-farm mortality rates}

Thomsen and Houe (2006) have studied dairy cow mortality or on-farm death rates and state that there is "no overview over what might be considered 'natural' or 'normal' level of mortality in dairy cow production". In the current study, the calculated mortality rate of $3.2 \%-4.1 \%$ (Table 3) is not dissimilar to comparable studies detailed by these authors. They reviewed 13 studies of dairy cow mortality and, in the study of Nørgaard et al. (1999), a crude death rate of between 3-4\%, in Denmark for the period 1974-1993, or Stephenson and Lean (1998) 4.3\%, in Australia, are similar to the rate in the Irish Republic. In Denmark, the mortality rate amongst cows has risen from $2 \%$ in 1990 to $4 \%$ in 2001 (Thomsen et al., 2007). Fetrow et al, (2006) put forward the proposition that cows reported as on-farm deaths will increase following the FDA 2004 rules prohibiting non-ambulatory cattle entering the food chain and the updating in 2005 of recommendations regarding humane transport. The mortality rate in Ireland increased from $3.2 \%$ (2003) to $4.1 \%$ (2006) as shown in Table 3. It is likely that the reported mortality rates have risen in Ireland for similar reasons consequential to revised rules for slaughter of casualty cattle post BSE, and also fitness to transport regulations.

\section{Why are animals culled?}

In most culling studies, determining reason(s) for culling is the primary objective of the study. For this reason, wellmanaged dairy herds are often chosen because of the high level of record keeping. In general, however, farmers do not record reasons for culling. Further, cows are frequently sold in open markets, without further detail as to whether they then move to slaughter or to other herds where they will continue to give economic return to their new keepers in the short or longer term.

This study covers the whole population, and provides an overview of culling in the broad spectrum of management on Irish cattle herds. To illustrate the potential variation, in cow fattening herds every cow is destined for culling in as short an interval as possible giving a culling rate of $100 \%$. In milk-recorded dairy herds, a cow's economic breeding index (EBI) will be taken into account and this also may result in higher than normal culling rates. In a pedigree herd, a cow with high genetic merit may survive an infertile year and/or continue to be used for the harvesting of ova.

Many studies give detailed account as to the reasons for culling and often an animal is culled for a number of reasons. Crosse et al. (undated) found that the primary reasons for culling are:

- Infertility/reproduction (23.5\%)

- Surplus (14.3\%)

- Low production and old age (13.4\%)

- Mastitis (12.1\%)

- Other reasons (36.7\%)

Secondary considerations, such as the age of a cow, will also be taken into account when deciding to cull for infertility problems. Bascom and Young (1988) also found that the most common primary reason for culling was infertility followed by mastitis and production, but that the decision to cull was a multi-factored decision influenced by factors such as age, breed and temperament.

There is some information, which may be gleaned from this study that may give assistance in helping the reader surmise a possible reason for the culling. The database records the interval between the last calving date and the date of the exit (Table 5). It would be reasonable to deduce that the longer the interval between the last calving date and the date of exit, the more likely that one of the reasons for culling is infertility. It could also mean the cow was a poor producer, did not thrive, was hard to fatten or was particularly thin. If that were the case, a farmer is likely to cut his/her losses and not persist with trying to fatten the animal. Similarly, the shorter the interval the more likely the reason is for disease/production difficulties.

\section{Conclusions}

The study found the average culling rate in Ireland over the four-year period was $19.6 \%$ for all cows, $21.3 \%$ for dairy-type cows and $18 \%$ for beef-type cows and, while the comparison with other published studies must be guarded because the base data is not fully compatible, the conclusion is that the overall rates of culling in Ireland fall within published internationally accepted norms. As a component of the culling rate, the on-farm mortality rate of $3.2-4.1 \%$ found in this study is likewise not outside rates found in comparable studies. In Ireland, $65-68 \%$ of dairy cows survive past their third lactation, which indicates a 
longer milking life than reported elsewhere. The study also found that average age of heifers calving and replacing culled cows was between 29.7 and 30.2 months, but span less than 18 months to more than 38 months.

There is only limited evidence as yet of the widely anticipated decrease in cattle numbers as a consequence of the change to decoupled payments following the 2003 reforms of the Common Agricultural Policy (CAP).

\section{Acknowledgements}

The authors are indebted to John Carroll of South Western Services for his invaluable assistance in conducting these analyses. The assistance of DAFF staff in National Beef Assurance Scheme and Information Systems Divisions is gratefully acknowledged.

\section{References}

Anon. (1997). Council Regulation (EC) No 820/97 of 21 April 1997 establishing a system for the identification and registration of bovine animals and regarding the labelling of beef and beef products. Official Journal of the European Communities L117: 1-8. 07 May 1997. Anon. (2000). Regulation (EC) No 1760/2000 of the European Parliament and of the Council of 17 July 2000 establishing a system for the identification and registration of bovine animals and regarding the labelling of beef and beef products and repealing Council Regulation (EC) No 820/97. Official Journal of the European Communities L204: 1-10. 11 August 2000.

Anon. (2003). CAP reform - a long-term perspective for sustainable agriculture, European Commission for Agriculture and Rural Development. http://ec.europa.eu/agriculture/capreform/index_en.htm. Accessed on 13 January 2008.

Bascom, S.S. and Young, A.J. (1988). A summary of the reasons why farmers cull cows. Journal of Dairy Science 81: 2299-2305. CMMS statistics report (2003). National Beef Assurance Division. The Department of Agriculture and Food, Dublin, Ireland.

CMMS statistics report (2004). National Beef Assurance Division. The Department of Agriculture and Food, Dublin, Ireland.

CMMS statistics report (2005). National Beef Assurance Division. The Department of Agriculture and Food, Dublin, Ireland.

CMMS statistics report (2006). National Beef Assurance Division. The Department of Agriculture and Food, Dublin, Ireland.

Crosse, S., Haran, P. and Killen, L. (undated). Replacement strategies to maximise profitability in dairying. Teagasc, Irish Agriculture and Food Development Authority. http://www.teagasc.ie/research/reports/ dairyproduction/4229/eopr-4229.htm. Accessed on 11 May 2006.

Crosse, S. and O'Donovan, S. (1998). Dairy cow disposal rates from commercial dairy farms participating in the DAIRYMIS II computerised management information system in Ireland. Irish Veterinary Journal 42: 75-78.

Esslemont, R.J. and Kossaibati, M.A. (1997). Culling in 50 dairy herds in England. Veterinary Record 140: 36-39.

Fetrow, J., Nordlund, K. V. and Norman, H. D. (2006). Culling:

nomenclature, definitions and recommendations. Journal of Dairy Science 89: 1896-1905.

Hadley, G.L., Wolf, C.A. and Harsh, S.B. (2006). Dairy cattle culling patterns, explanations, and implications. Journal of Dairy Science 89 2286-2296.

Norgaard, N.H., Lind, K.M. and Agger, J.F. (1999). Cointegration analysis used in a study of dairy-cow mortality. Preventive Veterinary Medicine 42 99-119.

Sol, J., Stelwagen, J. and Dijkhuizen, A.A. (1984). A three-year herd health and management program on thirty Dutch dairy farms. II. Culling strategy and losses caused by forced replacement of dairy cows. Veterinary Quarterly 6: $149-57$.

Stevenson, M.A. and Lean, I.J. (1998). Descriptive epidemiological study on culling and deaths in eight dairy herds. Australian Veterinary Journal 76: 482-488

Thomsen, P.T. and Houe, H. (2006). Dairy cow mortality: A review to evaluate the potential for meta-analysis. Proceedings of the $11^{\text {th }}$ International Symposium on Veterinary Epidemiology and Economics, 2006. http://www.Sciquest.org.nz

Thomsen, P.T., Østergaard, S., Sørensen, J.T. and Houe, H. (2007). Loser cows in Danish dairy herds: definition, prevalence and consequences. Preventive Veterinary Medicine 79: 116-135.

Whitaker, D.A., Kelly, J.M. and Smith, S. (2000). Disposal and disease rates in 340 British dairy herds. Veterinary Record 146: 363-7.

Whitaker, D.A., Macrae, A.I. and Burrough, E. (2004). Disposal and disease rates in British dairy herds between April 1998 and March 2002. Veterinary Record 155: 43-7. 